\title{
Transcending human spondyloarthritis: Implications of the ecologic record from the Permian to the present
}

\author{
Bruce Rothschild \\ Department of Medicine, West Virginia University, Morgantown, WV 26506 and Carnegie Museum, 4400 Forbes Ave, Pittsburgh, \\ PA 15215
}

\begin{abstract}
Spondyloarthropathy is recognized as far back as the Permian, 300 million years before present, increased in prevalence over geologic and modern time and is now essentially trans-mammalian in distribution. Four aspects allow spondyloarthropathy to be studied across phylogenetic lines and through time: Stability of disease characteristics and its spectrum, occurrence sufficiently early in life to for remains to be identified, absence of bias in skeletal preservation and lack of significant effect on organismal survival. Identified in mammal-like reptiles, dinosaurs and other more recent reptiles, it is with mammals that the disease became endemic. It strongly penetrated some early mammal lineages which were short-lived, in contrast to its geometric increase in population penetrance over geologic time. Prevalence increased seven fold in horses, rhinoceros and non-human primates and its current occurrence is independent of captive or free-ranging status. In addition to inflicting musculoskeletal morbidity, the disease is associated with behavior changes, some possibly related to interferon modulation. Spondyloarthropathy is considered a disease and rightly so, given its impact on mobility, health and behavior. However, it seems paradoxical that a phenomenon which has such negative effects would persist, let alone increase in population penetrance.
\end{abstract}

Keywords: animal model, behavior, evolution, spondyloarthroathy.

Inflammatory arthritis has a skeletal signature which has not undergone significant variation during the passage through geologic time and across the phylogenetic spectrum of reptiles and placental and marsupial mammals [1]. One can almost visualize the history of spondyloarthropathy as mammals completing a circle from the endodermic mammal-like reptiles (now extinct) to predominantly ectothermal dinosaurs and reptiles and then to endothermal placental mammals [1-7].

How can a disease be studied, not only today, but also through geologic time? Four major issues pertain: The first is the stability of disease characteristics and their variation. Diseases typically present epidemiologically as a spectrum, ranging from mild to severe, limited to extensive, with variable penetrance of their manifestations $[1,8,9]$. While difficulty might be encountered in attempting to diagnosis a single individual, the character of a given disease appears sufficiently reproducible as an epidemiological phenomenon to allow confident comparison of afflicted populations $[8,10,11]$. While that hypothesis has not been tested across the spectrum of disease, it has been validated for spondyloarthropathy $[1,6,9]$. The second issue is longevity. The population being evaluated must survive sufficiently long to develop the disease [1]. The denominator for epidemiologic study of that disease would be individuals who survived long enough for it to manifest. The third issue is the effect of the disease on subsequent longevity [1, 12]. If a disease significantly reduces longevity, estimates of population prevalence may well be skewed. The fourth issue is differential preservation [13]. Do individuals with the disease have a different taphonomic experience? Are their remains found in a different location than individuals without the disease? Does the disease alter the remains to reduce preservation of sentinel elements (e.g., bones)? The answer for these questions appears to be negative for all four questions $[1,6-8,10,11]$, supporting confidence in examining the paleo-epidemiology of spondyloarthropathy, its character and penetrance (population frequency) across phylogeny and through geologic time.

Limited number of examined Permian mammal-like reptiles precludes assessment of their disease prevalence, in contrast to modern reptiles and 
mammals [1, 14]. General assessment of the fossil record is limited by availability of sufficient sample size representing a single phylogeny or its development. Spondyloarthropathy is identifiable in a variety of dinosaurs including sauropods (e.g., Lufengosaurus huenei), ceratopsians (e.g., Triceratops), theropods (e.g., Tyrannosaurus rex) and hadrosaurs (e.g., Edmontosaurus) [1, 2, 15, 16] and marine reptiles (e.g., mosasaurs) [17], but surveys have been insufficient to allow assessment of prevalence. Monospecific bone beds (accumulations of the skeletons of a single dinosaur species) would seem to offer an opportunity to determine population prevalence, but difficulty assigning vertebral position compromises distinguishing multiple areas of fusion in a single individual from multiple affected individuals and, similarly, in determining the denominator (number of animals in the bone bed).

Insufficient samples have been identified to date to assess variation in spondyloarthropathy presence through geologic time in reptiles, with the exception of crocodylians and varanids [14, 18]. Less than one percent of current reptiles are affected. The varanids are especially prone to this disease, which affects $10 \%$ of Komodo dragons.

Review of spondyloarthropathy through time reveals no evolutionary changes in its character and prevalence in most mammalian lines [1, 4]. While trans-mammalian in distribution, most mammalian fossils either represents fossils in which low penetrance requires unrealistic sample sizes, are insufficiently represented or pertinent skeletal elements are not clearly demarcated or insufficiently researched [1]. Some early mammals such as the Eocene [ranging from 56 to 33.9 million years before present (ybp)] Coryphodon are well represented in the fossil record and spondyloarthropathy was common (20\%) [19]. Unfortunately that lineage did not survive the Epoch, so assessment of evolution of disease population penetrance is not possible. Coryphodon was unusual in its spondyloarthropathy-susceptibility in those early days of mammal evolution. It was also common in the Brontotheriidae (Two of four Dolichorhinus and one of two Megacerops available for examination), a lineage that was rarely represented in the Oligocene (ranging from 33.9 to 23 million ybp) and subsequently became extinct [1, 19].

Limited power of observations (measured as beta or type II error) is a major limiting factor in comparison of low prevalence disease occurrence, compromising validation of negative evidence [20]. Absence of evidence of change in prevalence of uncommon phenomenon or disorders does not confidently exclude change without a substantial sample set. Proving that occurrence rates of one to three percent are simply population variation and are not statistically significant would require over 800 individuals in each group being compared, if one wanted to be confident in only having a $20 \%$ change of being wrong. Almost 1000 are required in each group to reduce the error rate to $10 \%$. Compare this with the five percent level typically used to identify significant differences among samples and one quickly recognizes the limitations of the fossil record. Many factors affect whether a skeleton is preserved, how it fossilizes and how it is discovered [13]. The fossil record provides a window to a very small percentage of animals that lived at a given time and preservation is quite variable by species, the habitat and ecology of their environment. There, however, are two mammalian families that are both sufficiently represented and sufficiently identified as to their phylogeny in the fossil record to permit analysis of disease evolution or at least its population penetrance [21]. Among the perissodactylia, the phylogeny of horse and rhinoceros illustrates major variation in animal morphology, but not that of the afflicting disease, spondyloarthropathy. The disease manifestations in Oligocene relatives (33.9 to 23 million ybp) are indistinguishable from that of their contemporary descendants [21]. Population penetrance, however is not. Equines were too rarely represented in the Oligocene to assess occurrence of spondylarthropathy and the disorder was rare in Miocene (23 to $\sim 5$ million ybp) equines ( $1 \%$ ), but increased over geologic time to afflict eight percent of contemporary horses. The increase in prevalence is even more impressive in the rhinoceros lineage. Present in 5\% of Oligocene rhinoceros, today's prevalence is $35 \%$, independent (statistically) of species!

The evidence in non-human primates is just as impressive. Absent in Miocene apes, spondyloarthropathy is a significant affliction of modern great apes [1]: It is present in 20\% of contemporary gorilla (both lowland Gorilla gorilla gorilla and mountain Gorilla gorilla beringei), $28 \%$ of chimpanzees (both the common chimpanzee Pan troglodytes and the bonobo Pan paniscus) and $17 \%$ of orangutan (Pongo pygmaeus) [7, 22-29]. Prevalence of spondyloarthropathy was independent of captive or free-ranging status, in contrast to osteoarthritis, which is essential a disorder acquired from artificial (e.g., 
captive) environments $[30,31]$. This increase in prevalence of spondyloarthropathy over geological time is matched by changes observed during the $20^{\text {th }}$ century [5]. The prevalence in baboons (Papio anubiscynocephalus) in the 1920's and 1930's was 4\%. Ten percent were afflicted in the 1960's and 1970's. The prevalence in the 1980 's was $30 \%$ ! Rhesus macaques (Macaca mulatta) experienced a similar dramatic increase in prevalence [32].

Discussions of the holistic impact of spondyloarthropathy related to associated pain and disability should probably also include the impact of this impact on behavior. Could the reputation of rhinoceros for having a bad temper be related to the spondyloarthropathy afflicting one-third of their species [21]? The same question is reasonable to ask with respect to bear attacks. Twenty-five percent of bears have spondyloarthropathy [33]. If one is hurting and likely irritable or limited in foraging ability and an annoying, relatively slow, relatively defenseless human enters its lebensraum, is the bear more likely to attack? So far, these are untested hypotheses. The role of interferon in the pathogenesis of spondyloarthropathy [34] may also be a factor, given its role in induction of "social dysfunction" [35].

Spondyloarthropathy increased in prevalence over geologic and modern time and is now essentially transmammalian in distribution [1, 4, 5, 12, 21-26, 36-38]. This category of disease includes five subtypes: Ankylosing spondylitis, reactive arthritis, psoriatic arthritis, enteropathic (related to the gastrointestinal disorders, Crohn's disease and ulcerative colitis) derived and an undifferentiated form [1, 39, 40]. Among those, reactive diarrhea can be environmentally-derived. It is a known complication of infectious agent arthritis and certain venereallyacquired infections [39]. One consideration is that the increase in prevalence of disease reflects increased environmental contamination by such agents as Salmonella, Shigella, Yersinia, Camplobacter, enteropathic Escherichia coli, Chlamydia, Mycoplasma [41-45]? The very population prevalence of spondyloarthropathy makes that unlikely. The prevalence of spondyloarthropathy in animals maintained under variable sanitary conditions related to artificial environments (captivity) is not different from that in free-ranging animals [1, 23].

Further, the very prevalence precludes the consideration that infectious agents are an overriding component. The prevalence of spondyloarthropathy in human archeologic sites generally ranges from one to three percent [46]. There are several sites with greater prevalence. These were unusual historic sites in which sanitation was compromised [12]. The Highland Park (Rochester) poorhouse cemetery in upstate New York is across Lake Ontario from that of the Bellville Anglican Church. While disparate in "affluence," they did share a common municipal "behavior". They both accessed ice from Lake Ontario, with the carts that had just dumped human waste. The prevalence of spondyloarthropathy at those two sites was equivalent with each other [12], but significantly greater than that of other populations that did not share such environmental contamination [46]. However, the prevalence only maxed out at $8 \%$ [46] far less than the spondyloarthropathy "spikes" in non-human primates.

Spondyloarthropathy is considered a disease and rightly so, given its impact on mobility, health and behavior. However, it seems paradoxical that a phenomenon which has such negative effects would persist, let alone increase in population penetrance. The implication is that it may provide a benefit, as yet undiscovered. Could the pathophysiologic response responsible for the reactive arthritis resulting from infectious agent diarrhea improve afflicted organisms' resistance to more deadly effects of those infections, or could there be an indirect benefit? Two clear examples of such paradoxical benefit are sickle cell anemia and thalassemia, both related to abnormal hemoglobins that when present in the homozygous state cause significant morbidity and significantly shorten or even preclude post-natal life [47, 48]. Yet, they are prominently represented especially in people of Mediterranean heritage. While the homozygous state severely compromises the individual, the heterozygous state (abnormal gene present on only one chromosome, with normal gene on chromosome from other parent) alters blood such that the afflicted individual is less susceptible to malaria, while suffering minimally from the actual direct effect of the mutation [49]. Could a similar scenario explain not only the perseverance, but the actually increased penetrance of spondyloarthropathy through geologic and modern times? Is there some as yet unidentified benefit either to the development of this musculoskeletal disorder or is there a mutation or epigenetic phenomenon that conditions the individual to be more susceptible to the disease? Given that incomplete Freund's adjuvant (derived from Mycobacterium tuberculosis)-induced "animal models for rheumatoid arthritis" [50, 51] actually mimic spondyloarthropathy more closely $[1,9$, $40,52,53]$, that spondyloarthropathy and tuberculosis 
were sympatric in North America more than 6000 years [1] and that tuberculosis was not found in individuals with rheumatoid arthritis during this time period, one could speculate a relationship in which spondyloarthropathy or the alterations making individuals more susceptible to this arthritis might impact the development, severity or character of tuberculosis.

The variable penetrance (prevalence) of spondyloarthropathy among mammals was examined to identify clues to any potentially-related benefit. It was noted that larger animals were more commonly affected. Examination of carnivores and primates only revealed size/mass as a correlation, but did rule out effects related directly to population density, daily movement, group size, social interactions, promiscuity, arboreal versus fossorial versus ground dwelling, longevity, reproductive age, behavioral activities, parental care, herbivory versus carnivory and ornnivory, frugivory, folivory, ecology and availability of food resources. Increased population density and social contact, longevity, increased consumption of food resources (with related increase in infectious agent exposure), increased fecal contamination related to extended ground or water contact would support and infectious origin of disease [54-62], but none were found. Similar evaluation of domestic canids (dogs) revealed only size/mass as a correlate with prevalence of spondyloarthropathy [63, 64], but with significant breed variation- without obvious explanation: Chondrodsplastic (e.g., dachshund) were more commonly affected than non-chondrodysplastic (e.g., boxer, Doberman) dogs; sporting dogs (e.g., golden retriever), more than non-sporting (e.g., chow chow, bulldog) and hounds (e.g, beagle). Approximately onefourth of sporting dogs, terriers and toy dogs (e.g., pug, shih tsu) are affected. More than a third of working dogs (e.g., boxer, husky) are affected and almost half of herders (e.g., Collie, German shepherd).

\section{Conclusion}

Spondyloarthropathy is considered a disease and rightly so, given it impact on mobility, health and behavior. It has geometrically increased in population penetrance over geologic time. It seems paradoxical that a phenomenon which has such negative effects would persist, let alone increase in population penetrance. This suggests an as yet unrecognized organismal benefit, a subject worthy of further investigation.

\section{Conflicts of interest}

The author declares no conflicts of interest.

\section{References}

1. Rothschild BM, Martin LD. Skeletal Impact of Disease. New Mexico Museum of Natural History, Albuquerque 2006.

2. Rothschild BM. Origin of spondyloarthropathy in the Jurassic. Lancet 2002; 360: 1454. doi: $\quad 10.1016 / \mathrm{s} 0140-6736(02)$ 11471-1

3. Rothschild BM, Feldtkeller E. Spondyloarthritis in antiquity and history. In: Oxford Textbook of Axial Spondyloarthritis, Edited by Inman R, Sieper J. Oxford University Press, Oxford; 2016: 1-12. doi: 101093/med/ 9780198734444.001.0001.

4. Rothschild BM, Rothschild C Trans-mammalian pandemic of inflammatory arthritis (Spondyloarthropathy variety): Persistence since the Pleistocene. Paleontol Soc Publ 1996; 8: 330.

5. Rothschild BM, Rothschild C. Epidemic of spondyloarthropathy in baboons. J Med Primatol 1996; 25(1): 69-70. doi: 10.1111/j.1600-0684.1996. tb00196.x.

6. Rothschild BM, Woods RJ. Spondyloarthropathy: Erosive arthritis in representative defleshed bones. Amer J Phys Anthropol 1991; 85(2): 125-34. doi: 10.1002/ajpa. 1330850202.

7. Rothschild BM, Woods RJ. Reactive erosive arthritis in chimpanzees. Amer J Primatol 1991; 25(1): 49-56. doi: 10.1002/ ajp.1350250105.

8. Rothschild BM, Rothschild C. Treponemal disease revisited: Skeletal discriminators for Yaws, Bejel, and venereal syphilis. Clin Infect Dis 1995; 20(5): 1402-8. doi: 10.1093/clinids/ 20.5.1402.

9. Rothschild BM, Woods RJ, Rothschild C, Sebes JI. Geographic distribution of rheumatoid arthritis in ancient North America: Implications for pathogenesis. Semin Arthritis Rheum 1992; 22(3): 181-7. doi: 10.1016/0049-0172(92) 90018-9.
10. Rothschild BM. Paleopathology, its character and contribution to understanding and distinguishing among rheumatologic diseases: Perspectives on rheumatoid arthritis and spondyloarthropathy. Clin Exp Rheumatol 1995; 13(5): 657-62.

11. Rothschild BM, Woods RJ. Implications of osseous changes for diagnosis of spondyloarthropathy. J Orthop Rheumatol 1992; 5: 155-62.

12. Rothschild BM, Rothschild C. Nineteenth century spondyloarthropathy independent of socioeconomic status: Lack of skeletal collection bias. $J$ Rheumatol 1993; 20: 314-19.

13. Lyman RE. Vertebrate Taphonomy. University of Cambridge, Cambridge, 1994.

14. Rothschild BM, Schultze HP, Peligrini R. Herpetological Osteopathology: Annotated Bibliography of Amphibians and Reptiles. $\quad$ Springer-Verlag, 
Heidelberg, Germany, 2012.

15. Redelstorff R, Hayashi $\mathrm{S}$, Rothschild BM, Chinsamy A. Vertebral fusion in two Early Jurassic sauropodomorph dinosaurs from the Lufeng Formation of Yunnan, China. Acta Palaeontol Polon 2015; 60: 643-649.

16. Rothschild BM, Molnar RE 2008. Tyrannosaurid pathologies as clues to nature and nuture in the Cretaceous. In: Tyrannosaurus rex, the Tyrant King, Edited by Larson P, Carpenter K. Indiana University Press, Bloomington, 2008: 287306.

17. Rothschild BM, Everhart MJ. Coossification of vertebrae in mosasaurs (Squamata, Mosasauridae); Evidence of habitat interactions and susceptibility to bone disease. Trans Kansas Acad Sci 2015; 118 (3 \& 4): 265-75. doi: 10.1660/062.118.0309.

18. Rothschild BM. Macroscopic Recognition of Non-traumatic Osseous Pathology in the Postcranial Skeletons of Crocodilians and Lizards. J Herpetol 2010; 44(1): 13-20. doi: 10.1670/08243.1.

19. Rothschild BM, Sebes JI, Rothschild C. Antiquity of arthritis: Spondyloarthropathy identified in the Paleocene of North America. Clin Exp Rheumatol 1998; 16(5): 573-5.

20. Steel RG, Torrie JH. Principles and Procedures of Statistics, with Special Reference to the Biological Sciences. McGrawHill, New York, 1960.

21. Rothschild BM, Prothero DR, Rothschild C. Origins of spondyloarthropathy in Perissodactyla. Clin Exp Rheum 2001; 19(6): 628-32.

22. Rothschild BM. Arthritis in Callithrix jacchus: Calcium pyrophosphate deposition disease and spondyloarthropathy. $\boldsymbol{J}$ Med Primatol 1993; 22: 313-6.

23. Rothschild BM, Woods RJ Spondyloarthropathy in gorillas. Semin Arthritis Rheum 1989; 18(4): 267-76. doi: 10.1016/00490172(89)90048-6.

24. Rothschild BM, Woods RJ. Erosive arthritis and spondyloarthropathy in Old
World primates. Amer J Phys Anthropol 1992; 88(3): 389-400 doi: 10.1002/ajpa.1330880310.

25. Rothschild BM, Woods RJ. Spondyloarthropathy as an Old World phenomenon. Semin Arthritis Rheum 1992; 21(5): 306-16. doi: 10.1016/00490172(92)90024-8.

26. Rothschild BM, Woods RJ. Arthritis in New World monkeys: Osteoarthritis, calcium pyrophosphate deposition disease and spondyloarthropathy. Intl J Primatol 1993; 14(1): 61-78. doi: 10.1007/bf02196503.

27. Rothschild BM, Woods RJ. Inflammatory arthritis in Pongo. $\boldsymbol{J}$ Med Primatol 1996; 25(6): 414-8. doi: $\quad 10.1111 / \mathrm{j} .1600-0684.1996$. tb00037.x.

28. Rothschild BM, Rühli FJ. Comparison of arthritis characteristics in lowland Gorilla gorilla and mountain Gorilla beringei. Amer J Primatol 2005; 66(3): 205-18. doi: 10.1002/ ajp. 20139

29. Rothschild BM, Rühli FJ. Etiology of reactive arthritis in Pan paniscus, Pan troglodytes troglodytes and Pan schweinfurthii. Amer J Primatol 2005; 66(3): 219-31. doi: 10.1002/ajp.20140.

30. Rothschild BM. Osteoarthritis as a complication of artificial environment: The Cavia (guinea pig) story. Ann Rheumatic Dis 2003; 62(10): 1022-23. doi: 10.1136/ard.62.10.1022.

31. Rothschild BM, Hong N, Turnquist JE. Skeletal survey of Cayo Santiago rhesus: Osteoarthritis and apical plate excrescences. Semin Arthritis Rheum 1999; 29(2): 100-11. doi: 10.1016/s0049-0172(99)80041-9.

32. Rothschild BM, Hong N, Turnquist JE. Naturally occurring spondyloarthropathy in Cayo Santiago Rhesus macaques. Clin Exp Rheumatol 1997; 15(1): 45 51.

33. Rothschild BM, Wang XM, Cifelli R. Spondyloarthropathy in Ursidae: A Sexually Transmitted Disease? Natl Geographic Res Expl 1993; 9: 382-4.

34. Feng Y1, Ding J, Fan CM, Zhu P. Interferon- $\gamma$ contributes to HLAB27-associated unfolded protein response spondyloarthropathies.

Rheumatol 2012; 39(3): 574-82 doi: 103899/jrheum.101257.

35. Filianoi $\mathrm{A}, \mathrm{Xu} \mathrm{Y}$, Tustison $\mathrm{NJ}$, Marsh RL, Baker W, Smirnov I, et al. Unexpected role of interferon- $\gamma$ in regulating neuronal connectivity and social behavior. Nature 2016; 535(7612): $\quad 425-9 . \quad$ doi: 10.1038/nature18626.

36. Rothschild BM, Rothschild C. No laughing matter: Spondyloarthropathy in Hyaenidae. J Zoo Wildlife Med 1994; 25: 259-63.

37. Rothschild BM, Rothschild C, Woods RJ. Inflammatory arthritis in large cats: An expanded spectrum of spondyloarthropathy. J Zoo Wildlife Med 1998; 29: 279-84.

38. Rothschild BM, Rothschild C, Woods RJ. Inflammatory arthritis in canids: Spondyloarthropathy. $\boldsymbol{J}$ Zoo Wildlife Med 2001; 32(1): 58-64. doi: 10.1638/10427260(2001)032[0058: iaics]2.0. co;2.

39. Inman Rd, Perl A, Phillips PE. Infectious agents in chronic rheumatic disease. In: Arthritis and Allied Conditions: A Textbook of Rheumatology, Edited by Koopman WJ, $12^{\text {th }}$ edn. William \& Wilkins, Baltimore, 1997: 585-608.

40. Resnick D. Diagnosis of Bone and Joint Disorders. Saunders, Philadephia, 2002.

41. Ahvonen P, Sievers K, Aho K. Arthritis associated with Yersinia enterocolitica infection. Acta Rheum Scand 1969; 15(1-4): 232-53. doi: 10.3109/rhe1.1969. 15.issue-1-4.32.

42. Buxton JA, Fyfe M, Berger S, Cox MB, Northcott KA and the Multiprovincial Salmonella typhimurium Case-Control Study Group. Reactive arthritis and other sequelae following sporadic Salmonella typhimurium infection in British Columbia, Canada: A case control study. J Rheumatol 2002; 29(10): 2154-8.

43. Hannu T, Mattila L, Rautelin H, Pelkonen P, Lahdenne P, Siitonen A, et al. Campylobacter-triggered reactive arthritis: A populationbased study. Rheumatol 2002; 41(3): 312-8. doi: 10.1093/ rheumatology/41.3.312. 
44. Kvien TK, Glennas A, Melby K, Granfors K, Andrup O, Karstensen B, et al. Reactive arthritis: Incidence, triggering agents and clinical presentation. $\boldsymbol{J}$ Rheumatol 1994; 21(1): 115-22.

45. Zeidler H, Kuiopers J, Kohler L. Chlamydia-induced arthritis. Curr Opin Rheumatol 2004; 16(4): 380-92. doi: 10.1097/01.bor. 0000126150.04251.f9.

46. Rothschild BM, Woods RJ Character of pre-Columbian North American spondyloarthropathy. $J$ Rheumatol 1992; 19: 1229-35.

47. Muncie HL, Campbell J. Alpha and beta thalassemia. Amer Fam Phys 2009; 80: 339-44.

48. Steinberg B. Sickle Cell Anemia Arch Pathol 1930; 9: 876-97.

49. Aidoo M, Terlouw DJ, Kolczak MS, McElroy PD, ter Kuile FO, Kariuki S, et al. Protective effects of the sickle cell gene against malaria morbidity and mortality. Lancet 2002; 359(9314): 1311-2. doi: $\quad 10.1016 / \mathrm{s} 0140-6736(02)$ 08273-9.

50. Bendele AM. Animal models of rheumatoid arthritis. $J$ Musculoskel Neuron Interact 2001; 1(4): 377-85.

51. Carr AP, Michels G. Identifying noninfectious erosive arthritis in dogs and cats. Veterin Med 1997; 92: 804-10.

52. Rothschild BM. Two faces of "rheumatoid arthritis": Type A versus type B disease. J Clin Rheumatol 1997; 3(6): 334-8. doi: $10.1097 / 00124743$ 199712000-00006.

53. Rothschild BM, Woods RJ, Ortel W. Rheumatoid arthritis "In the buff": Erosive arthritis in representative defleshed bones. Amer J Phys Anthropol 1990; 82(4): 441-9. doi: 10.1002/ajpa. 1330820406

54. Anderson RM, May R.M. Infectious Diseases of Humans: Dynamics and Control. Oxford University Press, Oxford, UK, 1991

55. Arneberg P, Skorping A, Grenfell B, Read AF. Host densities as determinants of abundance in parasite communities. Proc R Soc Lond Ser B 1998; 265(1403): 1283-9. doi: 10.1098/rspb.1998. 0431

56. Harvell CD, Kim K, Burkholder JM, Colwell RR, Epstein PR, Grimes DJ, et al. Emerging marine diseases: climate links and anthropogenic factors. Science 1999; 285(5433): 1505-10. doi: 10.1126/science.285.5433.1505.

57. Møller AP, Dufva R, Allander K. Parasites and the evolution of host social behavior. Adv Study Behav 1993; 22: 65-102. doi: 10.1016/s0065-3454(08)60405-2.

58. Moore, J. Parasites and the
Behavior of Animals. Oxford University Press, Oxford, UK, 2002.

59. Nunn CL, Altizer SM. Infectious Diseases in Primates: Behavior, Ecology and Evolution. Oxford University Press, Oxford, UK, 2006.

60. Nunn CL, Altizer S, Jones KE, Sechrest W. Comparative tests of parasite species richness in primates. Amer Nat 2003; 162(5): 597-614. doi: 10.1086/378721.

61. Nunn CL, Gittleman JL, Antonovics J. Acomparative study of white blood cell counts and disease riskin carnivores. Proc $R$ Soc London Seri B Biol Sci 2003; 270(1513): 347-56. doi: 10.1098/rspb.2002.2249.

62. Poulin R, Morand S. Parasite Biodiversity. Smithsonian Institution Press, Washington, DC; 2004.

63. Rothschild B, Breit S. Recognition and breed specificity of canine spondyloarthropathy. $\boldsymbol{J}$ Spine 2016; 43: 1251-2.

64. Nunn C, Rothschild BM, Gittleman J. Why are some species more commonly afflicted by arthritis than others? A comparative study of spondyloarthropathy in primates and carnivores. J Evol Biol 2007; 20(2): 460-70. doi: 10.1111/j. 1420-9101.2006.01276.x. 